\title{
ANALISIS PERFORMANSI PROTOKOL ROUTING DISTANCE VECTOR DAN HYBRID ROUTING DENGAN ROUTER PROPRIETARY
}

\section{PERFORMANCE ANALYSIS OF DISTANCE VECTOR ROUTING PROTOCOL AND HYBRID ROUTING WITH PROPRIETARY ROUTER}

\author{
Muhammad Iqbal \\ Prodi D3 Teknik Telekomunikasi, Fakultas Ilmu Terapan, \\ Universitas Telkom \\ iqbal@tass.telkomuniversity.ac.id
}

\begin{abstract}
Abstrak
Protokol routing merupakan metode yang digunakan untuk menghubungkan dari router satu ke router yang lainnya, menyampaikan informasi dengan benar, memberikan jaminan layanan. Setiap protokol routing memiliki algoritma yang berbeda, pada penelitian ini dibahas tentang protokol routing yang bersifat distance vector dan hybrid routing, khusus penelitian ini akan dibahas tentang protokol routing yang bersifat proprietary.

Skenario yang digunakan pada penelitian ini menggunakan komunikasi VoIP (Voice over Internet Protocol), dengan menggunakan 10 buah router, 16 host yang berkomunikasi satu dengan lainnya pada saat yang bersamaan, kemudian juga dilakukan scenario pemutusan jaringan untuk melihat cara protokol routing meng-update tabel routingnya, juga akan dilakukan perbandingan antara performansi antara IPv4 dan IPv6.

Dari hasil penelitian didapatkan hasil protokol routing EIGRP dibandingkan dengan IGRP memiliki nilai performansi dari sisi konvergensi jaringan, jumlah hop, paket yang hilang (traffic dropped), delay paket dan throughput yang lebih baik.

Kata kunci : Distance vector, Hybrid Routing, Proprietary
\end{abstract}

\begin{abstract}
Routing protocol is a method used to connect from one router to another router, convey information with correctly, providing service guarantees. Each routing protocol has a different algorithm, in this research discussed about routing protocols are distance vector and hybrid routing, special research will be discussed on proprietary routing protocols.

In this scenario using VoIP (Voice over Internet Protocol), using 10 pieces of routers, 16 hosts communicate with each other at the same time, then also we have do network termination scenarios to see how the routing protocol updates its routing tabel, also will be a comparison between the performance of IPv4 and IPv6.

From the results, the results of the EIGRP routing protocol compared to IGRP has a value of performance of the network convergence, the number of hops, packets lost (dropped traffic), packet delay and throughput have a better value.
\end{abstract}

Keyword : Distance vector, Hybrid Routing, Proprietary

\section{PENDAHULUAN}

Perkembangan jaringan telekomunikasi tidak terlepas pada jaringan komputer itu sendiri, terutama pada protokol routing, dewasa ini telah banyak perkembangan protokol routing 
disebabkan kebutuhan manusia yang semakin kompleks akan komunikasi jarak jauh [1], sehingga penelitian tentang routing tidak dapat dihindarkan. Perkembangan protokol routing dilakukan dengan berbagai macam cara, mulai dari yang bersifat Open Source sampai dengan yang bersifat Proprietary (bersifat tertutup dan biasanya milik suatu produk/vendor). Protokol routing mengarah kepada protokol yang berbasis dinamis, karena fleksibilitas kebutuhan dan juga kompleksitas jaringan yang beragam. Menjadi sangat tidak cocok jika penerapan protokol routing statis ditempatkan untuk jaringan yang berskala besar, akan menghabiskan banyak waktu dan tenaga untuk mengkonfigurasi jaringan komputer.

Penelitian-penelitian tentang protokol routing statis dan dinamis telah banyak dilakukan oleh beberapa peneliti, pada penelitian kali ini penulis mencoba untuk menggunakan aplikasi OPNET untuk melihat keterkaitan antara teori dengan hasil simulasi yang didapat, sehingga menjadi bahan pertimbangan kedepannya dalam pemilihan protokol routing sesuai dengan kebutuhan.

Pada penelitian ini akan arahkan pada pembahasan protokol routing yang bersifat dinamis, khususnya yang bersifat proprietary, ini dikarenakan masih sedikit peneliti membahas tentang protokol yang bersifat tertutup ini. Proprietary yang dimaksud adalah menggunakan produk perusahaan Cisco Router, adapun Protokol routing yang digunakan adalah jenis dari Interior Gateway Routing Protokol (IGRP), Enhanced IGRP (EIGRP), dan EIGRP untuk IPv6[2]. Penulis lebih menekankan kepada protokol routing yang bersifat hybrid (distance vector dan link state).

Pada penelitian ini lebih ditekankan pada protokol routing yang bersifat distance vector dan hybrid, melakukan kajian tentang cara kerja dari masing-masing protokol, serta melakukan analisa tentang konvergensi jaringan dilihat dari sisi waktu, jumlah hop yang akan dilalui oleh masing-masing router, dan penilaian terhadap Quality of Service (QoS) dengan parameter traffic dropped (paket yang hilang), delay paket dan throughput.

\section{DASAR TEORI}

\subsection{Routing Dinamis [3]}

Komponen yang paling terpenting pada lapis network TCP/IP adalah protokol routing, protokol routing memiliki 3 jenis yaitu statis, dinamis dan default. Protokol routing secara dinamis berkomunikasi untuk memilih rute terbaik untuk mencapai tujuan. Paket diteruskan (forward) dari satu router ke router yang lain. Saat ini sudah banyak protokol routing yang dikembangkan, seperti RIP, IGRP, EIGRP, OSPF, IS-IS, dan lain sebagainya. Ada yang bersifat open (terbuka dan didukung berbagai vendor perangkat), ada juga yang bersifat proprietary (hanya untuk perangkat buatan vendor tertentu).

Jika ditinjau dari sisi algoritma atau prosesnya maka protokol routing dapat dibagi menjadi :

a) Distance vector

Merupakan jenis protokol routing lama, beberapa ciri dari distance vector adalah

1) Distance atau jarak untuk mencapai tujuan akhir. Distance dapat ditentukan berdasarkan cost yang ditentukan dari jumlah host (hitungan hop) yang dilalui rute atau jumlah total perhitungan metric pada rute tersebut. Informasi diperoleh dari router tetangga yang terhubung langsung dengannnya.

2) Vector

Vector merupakan arah traffic. Ketika data akan di-forward ke tujuan maka data tersebut pasti akan melalui network interface hingga dapat mencapai tujuan.

3) Perubahan topologi network biasanya akan direspon oleh protokol secara lambat. Istilahnya adalah slow convergence

4) Merupakan clasfull routing protokol, artinya tidak mendukung Variable Length Subnet Mask (VLSM) dan Classless Inter Domain Routing (CIDR). 
5) Tidak mudah diimplementasikan pada network berskala besar, kurang dari 100 router.

b) Link state

6) Menggunakan algoritma Bellman Ford.

Merupakan jenis protokol routing yang lebih baru. Beberapa ciri link state :

1) Link state dapat menentukan status dan tipe koneksi setiap link dan menghasilkan sebuah perhitungan metric berdasarkan beberapa factor termasuk yang ditentukan oleh network administrator.

2) Protokol dapat mengetahui apakah link sedang up atau down, dan dapat mengetahui seberapa cepat untuk mencapai kesana. Link state akan memilih rute tercepat meskipun harus melalui banyak network interface, dibandingkan rute yang lambat meskipun hanya terdapat sedikit network interface.

3) Dapat mengetahui perubahan topologi network dengan cepat, yang disebut dengan fast convergence.

4) Merupakan classless routing protokol, artinya mendukung Variable Length Subnet Mask (VLSM) dan Classless Inter Domain Routing (CIDR).

5) Cocok diimplementasikan pada network skala besar.

c) Hybrid

6) Menggunakan algoritma Djikstra.

Protokol jenis hybrid merupakan gabungan dari sebagian fitur distance vector dan link state. Sebagai contoh yaitu protokol EIGRP yang dikembangkan oleh Cisco. Fakta menunjukkan bahwa distance vector cocok digunakan untuk network yang jarang mengalami perubahan topologi atau network yang dibentuk oleh router-router dengan jenis interface card yang sama (speed dan bandwidth yang sama). Untuk kondisi semacam ini maka proses penentuan path dapat dilakukan secara sederhana dan akurat dan jauh lebih cepat dibandingkan dengan link state.

Namun jika network relative dinamis, mudah berubah, dan terdiri atas gabungan berbagai interface yang berbeda-beda maka link state akan lebih unggul dibandingkan distance vector. Protokol hybrid dikembangkan untuk mengantisipasi kedua kondisi ini. Sederhana dalam perhitungan namun cukup fleksibel untuk mengantisipasi perubahan network[4].

\subsection{Interior Gateway Routing Protocol (IGRP) [5]}

IGRP merupakan jenis protokol yang bersifat proprietary. IGRP diciptakan untuk mengatasi keterbatasan RIP (hop maksimum hanya 15) dan hanya dapat digunakan untuk jaringan berskala kecil. IGRP mendukung beberapa metrik untuk setiap rute, termasuk bandwidth, delay, beban, MTU, dan keandalan. Secara default, IGRP memiliki nilai administrative distance secara default 100, dan routing update dilakukan setiap 90 detik (secara default). IGRP menggunakan port nomor 9 untuk proses komunikasi.

IGRP bersifat protokol routing classful, karena IGRP tidak mampu membagi kelas secara lebih kecil lagi, hanya mampu sesuai dengan subnet mask. Protokol classful telah menjadi kurang populer karena protokol ini boros penggunaan alamat IP.

Protokol IGRP memungkinkan sejumlah gateway untuk mengkoordinasikan routing. Tujuannya adalah sebagai berikut:

- Memiliki routing yang stabil dalam jaringan yang berskala besar atau kompleks dibandingkan dengan RIP. Tidak ada routing yang loop yang terjadi.

- Respon yang cepat terhadap perubahan topologi jaringan.

- Overhead rendah. Artinya, IGRP sendiri tidak menggunakan bandwidth lebih dari apa yang sebenarnya dibutuhkan untuk melakukan tugasnya.

- Dapat diinterkoneksi dengan routing protokol yang berbeda. 
Tabel 1. Perbandingan Karakteristik IGRP dan EIGRP [6]

\begin{tabular}{|l|l|l|}
\hline Karakteristik & IGRP & EIGRP \\
\hline Jenis Protokol & Distance vector & Hybrid Routing \\
\hline Dukungan Classless & Tidak & Ya \\
\hline Dukungan VLSM & Tidak & Ya \\
\hline Auto-Summarization & Ya & Ya \\
\hline Route Propagation & Periodik Update Routing & Periodik \\
\hline Path Metric & Bandwidth, Delay & $\begin{array}{l}\text { Bandwidth, Delay, Load } \\
\text { dan Reliability }\end{array}$ \\
\hline Hop Count Limit & 255 & 255 \\
\hline Convergence Time & Slow & $\begin{array}{l}\text { Fast } \\
\text { Algorithm (DUAL) Update }\end{array}$ \\
\hline Algoritma & Bellman-Ford & \\
\hline
\end{tabular}

\subsection{Enhanced Interior Gateway Routing Protocol (EIGRP) [3]}

Internet dapat dipandang sebagai sebuah jaringan computer berukuran raksasa yang dibentuk menggunakan topologi mesh. Sedangkan yang menjadi node-nodenya adalah routerrouter. Pada router terdapat tabel routing. Tabel routing berisi daftar rute yang terbaik untuk mencapai tujuan. Tabel routing bersifat dinamis dan selalu diperbarui (di-update) berdasarkan informasi yang diperoleh dari router tetangga[7].

Konvergensi adalah bagian dari proses update tabel routing. Ketika link gagal atau ada perubahan rute, informasi terbaru dikirim ke seluruh jaringan yang menggambarkan perubahan dalam topologi jaringan. Setiap router kemudian menjalankan algoritma routing, melakukan perhitungan ulang, dan membangun tabel routing baru. Setelah semua router memperbarui tabel routing-nya maka konvergensi selesai. Konvergensi merupakan proses routing dinamis, dimana update tabel routing terjadi secara otomatis. Protokol routing dinamis sangat cocok untuk network besar, sedangkan protokol routing statis cocok untuk network yang berskala kecil.

\subsection{IPv6}

IPv6 diciptakan karena kebutuhan penggunaan IP di dunia ini yang banyak, IPv4 tidak cukup untuk menampung kebutuhan pengalamatan, karena IP bersifat unik yang artinya satu perangkat dengan perangkat yang lain tidak diperkenankan mempunyai identitas yang sama. IPv6 memiliki panjang 128 bit sedangkan IPv4 hanya memiliki panjang alamat 32 bit[8]. IPv6 memiliki jumlah kombinasi alamat sebanyak $2^{128}$ dengan 36 buah angka nol di belakangnya.

\section{ARSITEKTUR JARINGAN}

Berikut merupakan skenario yang digunakan dalam simulasi. Ada beberapa komponen hardware yang digunakan adalah 10 buah Router dengan tipe 7200 cisco, 4 buah Switch Ethernet, 16 buah PC yang digunakan sebagai host, untuk berkomunikasi satu dengan lainnya. Jenis layanan yang digunakan adalah VoIP (Voice over IP) dengan menggunakan codec bertipe GSM Quality Speech, fungsi 16 buah PC dilibatkan pada saat yang bersamaan untuk melihat kemampuan dari protokol routing yang digunakan, juga digunakan dalam skenario pemutusan jaringan antara Router 1 - Router 2, Router 1 - Router 3, Router 1 - Router 4, yang dilakukan secara bergantian, proses pengambilan data membutuhkan waktu 20 menit untuk setiap skenario failover dan recoverynya. Arsitektur jaringan dapat dilihat pada Gambar 1. 


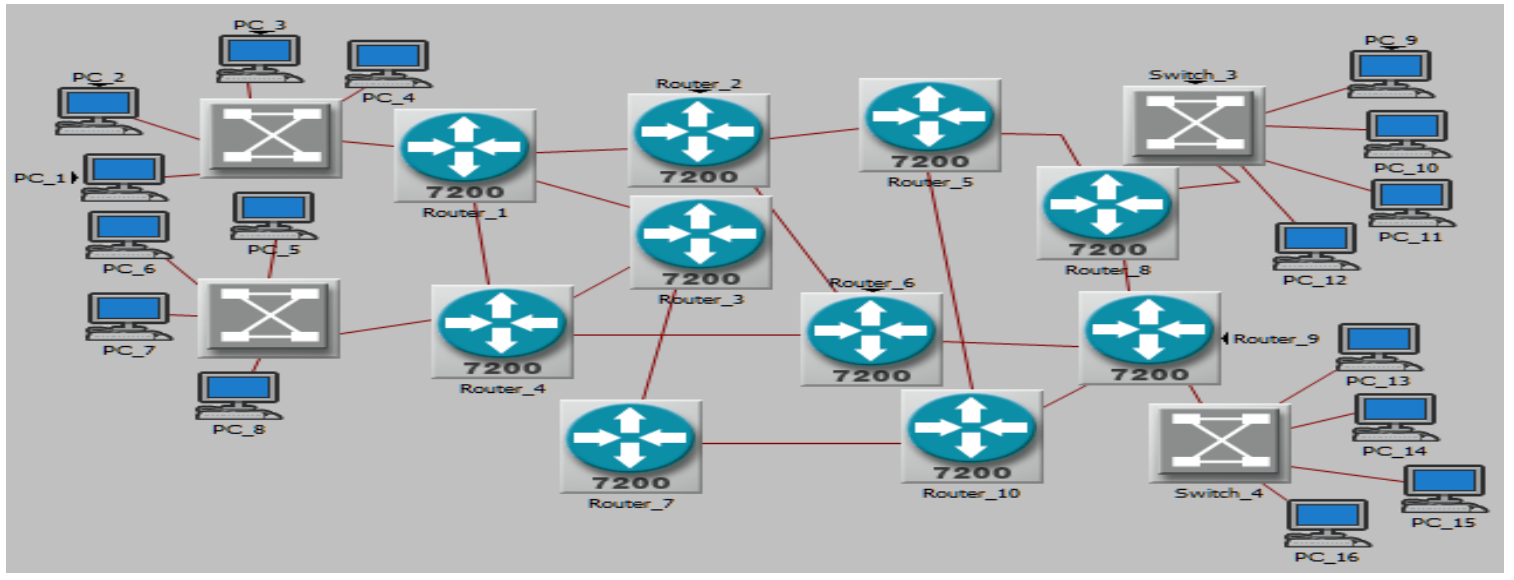

Gambar 1. Arsitektur Jaringan Protokol Routing IGRP-EIGRP

\section{PEMBAHASAN}

Pada penelitian ini, penulis menggunakan network simulator, Optimized Network Engineering Tools (OPNET), sistem dibuat dengan membangkitkan paket discrete event system (DES), network simulator ini menggunakan bahasa pemrograman $\mathrm{C}$ dan $\mathrm{C}++$, sehingga pengembangan terhadap objek dapat dikembangkan sendiri, tidak terlepas pada sistem yang tertutup (proprietary system)[2]. Fitur utama dari OPNET adalah aplikasi ini menyediakan alat yang membantu pengguna dalam tahap desain pemodelan dan simulasi Project, yaitu pembangunan model, pelaksanaan simulasi dan analisis data output. OPNET mempekerjakan struktur hirarkis untuk pemodelan, yaitu setiap tingkat hirarki menggambarkan aspek yang berbeda dari model yang lengkap. OPNET memiliki library dari model-model yang memberikan dukungan untuk protokol yang ada dan memungkinkan peneliti dalam pengembangan untuk memodifikasi model-model yang sudah ada atau mengembangkan model-model baru. Selain itu, model OPNET dapat dikompilasi ke dalam kode executable. Sebuah simulasi discrete-event dapat melakukan debugged atau hanya dieksekusi, sehingga didapatkan data output.

Jenis protokol routing yang digunakan pada penelitian ini adalah

1. IGRP dengan menggunakan pengalamatan IPv4

2. EIGRP dengan menggunakan pengalamatan IPv4

3. EIGRP dengan menggunakn pengalamatan IPv6

\subsection{Konvergensi Jaringan}

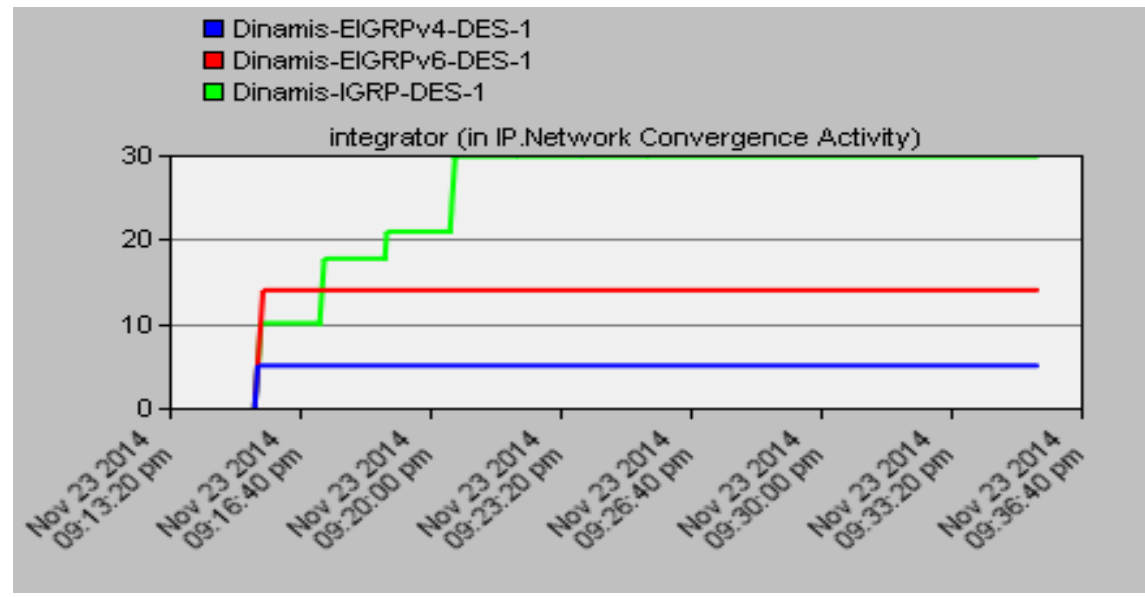

Gambar 2. Konvergensi Jaringan 
Pada Gambar 2 diatas dapat dilihat bahwa protokol routing IGRP membutuhkan waktu yang lebih lama untuk dibandingkan dengan protokol routing EIGRP, sementara untuk hasil antara EIGRP untuk IPv6 dengan IPv4, lebih cepat EIGRPv4 karena pengalamatan IPv4 lebih pendek dibandingkan dengan IPv6, sehingga EIGRPv6 lebih lambat dibandingkan dengan EIGRPv4.

\subsection{Jumlah Hop}

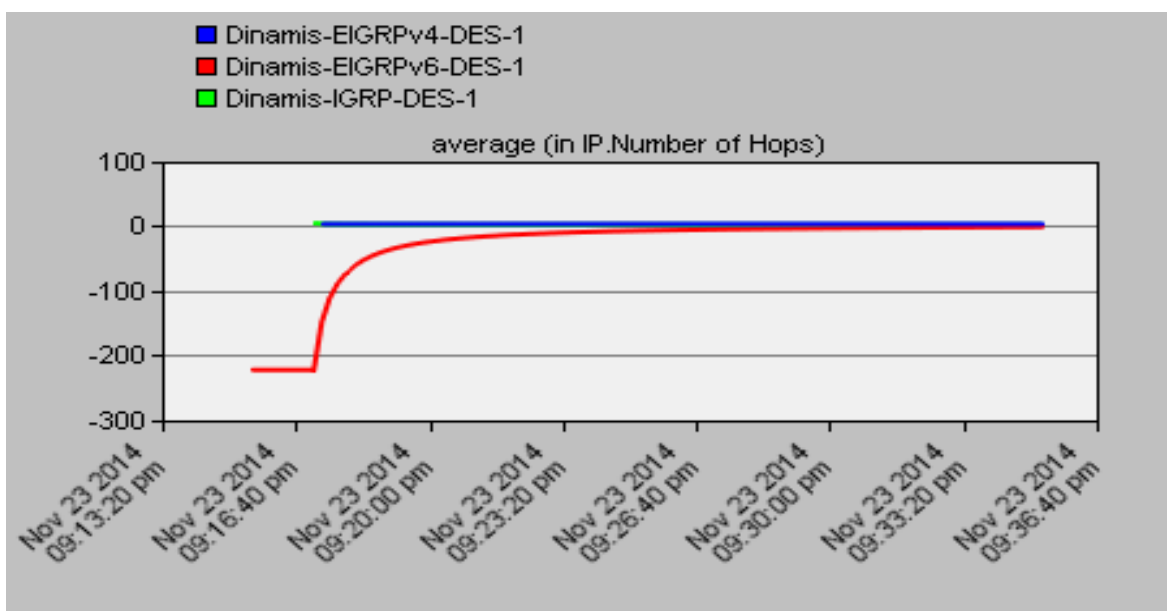

Gambar 3. Jumlah Hop

Terlihat bahwa grafik menunjukkan bahwa IGRP bersifat distance vector, dengan menggunakan algoritma bellman-ford, sehingga pada algoritma ini masih diperbolehkan untuk hasil minus (-), minus disini dimaksudkan adalah sebagai revese routing ke arah sebaliknya dari tujuan, karena tujuan mengalami link down.

\subsection{Jumlah Paket Hilang}

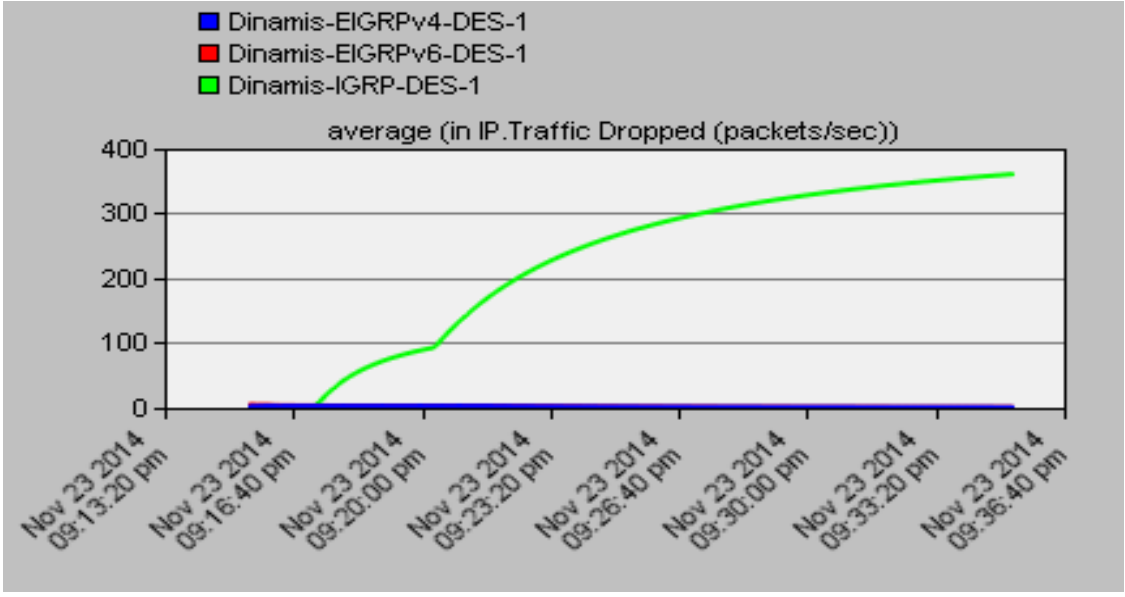

Gambar 4. Jumlah Paket Hilang

Pada Gambar 4 didapatkan hasil bahwa protokol routing IGRP memiliki jumlah packet dropped (paket yang hilang) lebih banyak dibandingkan dengan protokol routing EIGRP, EIGRP terlihat stabil pada 0\% kehilangan paket data. Ini menjadikan EIGRP protokol routing yang lebih baik daripada IGRP untuk jenis packet dropped (kehilangan paket data). 


\subsection{Variasi Delay}

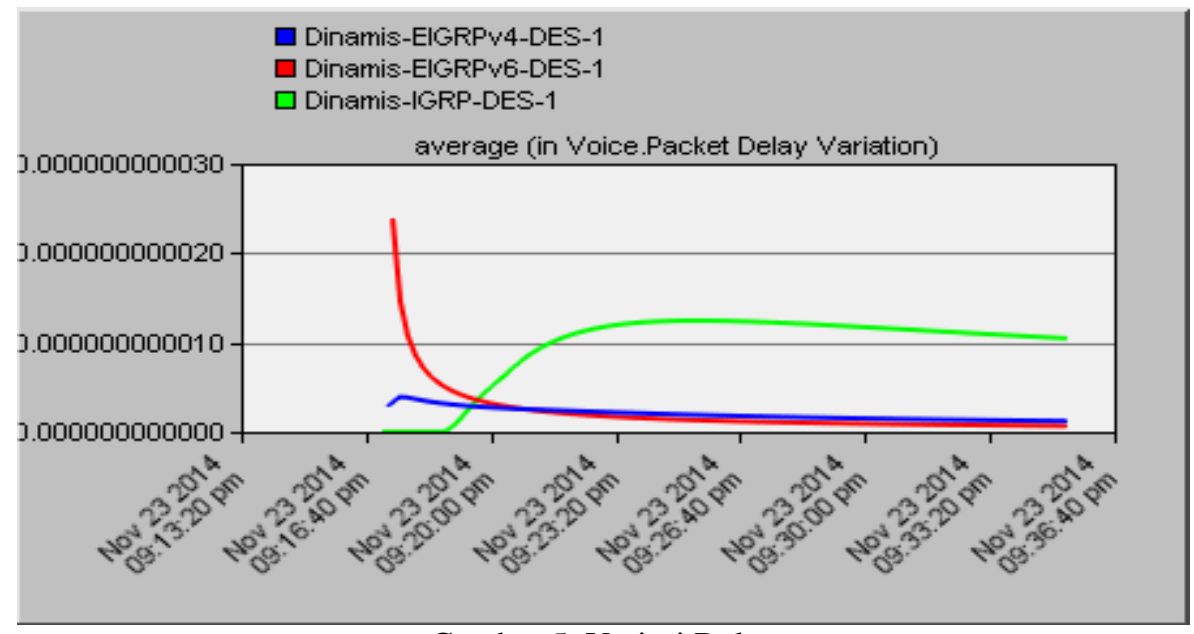

Gambar 5. Variasi Delay

Pada Gambar 5, Terjadi fluktuatif variasi delay atau yang lebih sering disebut dengan Jitter, pada EIGRPv6, di menit awal masih belum stabil, untuk selanjutnya variasi delay cenderung menurun, yang terjadi pada IGRP variasi delay cenderung meningkat, ini mengakibatkan pengiriman data menjadi lebih lama.

\subsection{Throughput Voice}

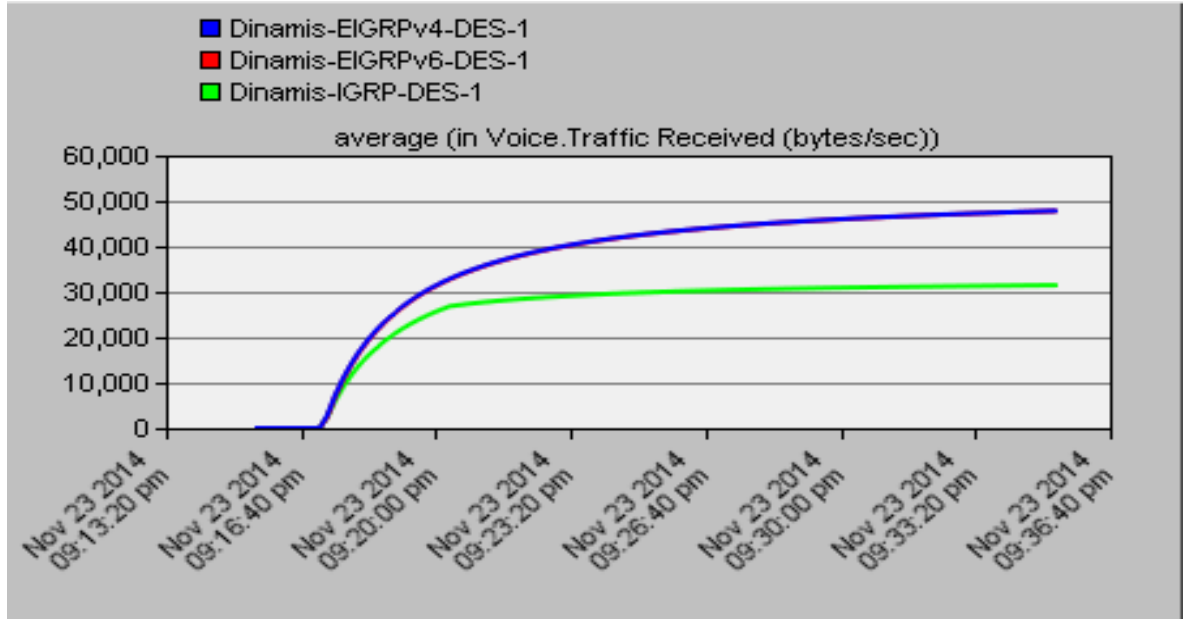

Gambar 6. Throughput Voice

Pada Gambar 6, memperlihatkan throughput yang dihasilkan pada pembangkitkan sinyal suara (Voice), didapatkan bahwa throughput yang dihasilkan antara EIGRP menghasil nilai yang lebih baik dibandingkan dengan protokol routing IGRP.

\section{KESIMPULAN}

Protokol routing yang bersifat distance vector dan hybrid routing memiliki kemampuan atau karakteristik masing-masing, sehingga tidak dapat dikatakan dengan mutlak bahwa hybrid lebih baik dibandingkan dengan distance vector. Dari hasil simulasi yang didapatkan, dari sisi angka memang terlihat dengan jelas baik untuk konvergensi jaringan, jumlah hop, paket yang hilang, variasi delay dan throughput yang dihasilkan EIGRP lebih baik dibandingkan IGRP. Saran 
untuk penelitian selanjutnya, agar dilakukan penelitian antar sesame protokol routing distance vector, sehingga didapatkan pengambilan keputusan untuk implementasi jaringan berskala kecil.

\section{DAFTAR PUSTAKA}

[1] P. Rakheja, P. Kaur, A. Gupta, and A. Sharma, "Performance Analysis of RIP , OSPF , IGRP and EIGRP Routing Protocols in a Network," Int. J. Comput. Appl. (0975 - 888), vol. 48 , no. 18 , pp. 6-11, 2012.

[2] J. Singh and Rajiv Mahajan, "International Journal of Advanced Research in Computer Science and Software Engineering Simulation Based Comparative Study of RIP, OSPF and EIGRP,” Int. J. Adv. Res. Comput. Sci. Softw. Eng., vol. 3, no. 8, pp. 285-288, 2013.

[3] I. Sofana, Cisco CCNP dan Jaringan Komputer, First Edit. Bandung: Informatika, 2012.

[4] A. Verdejo, "Implementing and analyzing in Maude the Enhanced Interior Gateway Routing Protocol," pp. 1-17, 2008.

[5] C. System, "An Introduction to IGRP," 2005. [Online]. Available: http://www.cisco.com/c/en/us/support/docs/ip/interior-gateway-routing-protocoligrp/26825-5.html. [Accessed: 25-Nov-2014].

[6] R. Kumar, J. Vats, and A. Kumar, "A Comparative Study of Routing Protocols," vol. 2, no. 5, pp. 1962-1964, 2011.

[7] R. M. Pethe and S. R. Burnase, "TECHNICAL ERA LANGUAGE OF THE NETWORKING - EIGRP,” pp. 1-5, 2011.

[8] A. O. Airlangga, T. I. Informatika, A. Dalam, R. Protocol, R. Protocol, E. Interior, G. Routing, and R. Eigrp, "Analisis Perbandingan Performansi Routing Protocol EIGRP dan IS-IS Pada IPv6 Performance Comparison Analysis Between EIGRP and IS-IS Routing Protocol on IPv6," pp. 1-8. 